\title{
DETERMINAÇÃO DE METODOLOGIA PARA O ISOLAMENTO DE PROTOPLASTOS DE TANGERINA CLEÓPATRA (Citrus reshni Hort.)
}

\author{
R.P. de OLIVEIRA; B.M.J. MENDES; A. TULMANN NETO \\ Centro de Energia Nuclear na Agricultura/USP - C.P. 96 - CEP: 13400-900- Piracicaba, SP.
}

\begin{abstract}
RESUMO: A hibridação somática via fusão de protoplastos vem sendo utilizada no melhoramento de porta-enxertos de citros em diversos países. Nos Estados Unidos, vários estudos demonstram a eficiência de procedimentos no isolamento e cultivo de protoplastos dessa frutifera. $O$ presente trabalho foi realizado com o objetivo de avaliar 0 efeito do meio de cultivo de calos embriogenicos do porta-enxerto tangerina Cleopatra (Cirus reshni Hort.) sobre 0 isolamento de protoplastos, bem como sugerir alteraçōes de procedimento. Os resultados mostram a possibilidade do isolamento de $1.4 \times 10^{6}$ a $4.7 \times 10^{6}$ protoplastos por grama de calos da espécie estudada. Verificou-se que, o subcultivo dos calos de tangerina Clépatra em meio de cultura, sem reguladores de crescimento suplementado com apenas $4 \%$ de sacarose e emprego de um pré-tratamento enzimático com macerozyme a $1 \%$ por 1 hora, sob condições de escuro a $120 \mathrm{rpm}$, proporcionou maior eficiência de isolamento de protoplastos $\left(4.7 \times 10^{\circ}\right.$ protoplastos $/ \mathrm{g}$ de calo).
\end{abstract}

Descritores: tangerina Cle6patra, protoplastos, isolamento

\section{METHODOLOGY CHOICE FOR PROTOPLAST ISOLATION IN CLEOPATRA MANDARIN (Citus reshni Hort.)}

\begin{abstract}
AASTRACT: Somatic hybridization has been used for citrus rootstock breeding in many countries. In USA, many reports had proved the efficiency of procedures for the isolation and culture of citrus protoplasts. This research was conducted to evaluate the efficiency of procedures of protoplast isolation using embryogenic callus of the Cleopatra mandarin rootstock. Alterations were proposed to increase protoplast isolation and culture method. Results show the possibility of a protoplast yield of 1.4 to $4.7 \times 10^{6} \mathrm{pps} / \mathrm{g}$.f.w. for Cleopatra tangerine rootstock callus. Protoplast yield can be raised to $4.7 \times 10^{6} \mathrm{pps} / \mathrm{g}$.f.w. if the embryogenic callus are grown in a medium supplemented only with 4\% sucrose and pre-treated with $1 \%$ w/v macerozyme for 1 hour, at $120 \mathrm{rpm}$, in dark, is applied before protoplast isolation.
\end{abstract}

Key Words: Cleopatra mandarin, protoplast, isolation

\section{INTRODUÇÃO}

O Brasil é o maior produtor e exportador de suco cítrico concentrado (FAO, 1992). A diversificação do material genético dos pomares com variedades de enxertos e portaenxerto tolerantes a pragas, doenças e estresses de natureza abiótica consiste na medida mais racional para sustentação dessa posição no mercado internacional.

Nos últimos anos, a hibridação somática via fusão de protoplastos passou a ser empregada no melhoramento de variedades de citros em diversos países, tendo sido obtidos inúmeros híbridos somáticos que, atualmente, estão sendo avaliados a nível de campo (OHGAWARA et al., 1985 e GROSSER \& GMITTER Jr., 1990). Esses híbridos somáticos apresentam a vantagem de serem alotetraplóides, mantendo os genes parentais por não apresentarem segregação meiótica. Assim, as características favoráveis e desfavoráveis controladas por genes dominantes ou codominantes presentes em um dos pais podem se expressar, ao contrário dos genes deletérios recessivos, frequentemente presentes nas variedades cítricas, que não se expressam (GROSSER \& GMITTER Jr., 1990).

A hibridação somática de citros vem sendo utilizada como rotina em laboratórios dos Estados Unidos, Israel e Japão, porém trabalhos relacionados ao isolamento, purificação e cultivo de protoplastos são escassos no Brasil. 
Desta forma, o presente trabalho teve por objetivo avaliar o efeito do meio de cultivo de calos embriogênicos do porta-enxerto tangerina Cleópatra (Citrus reshni Hort.) sobre o isolamento de protoplastos ao utilizar-se o protocolo descrito por GROSSER \& GMITTER Jr. (1990), bem como sugerir alterações em seu conteúdo visando aumentar sua eficiência.

\section{MATERIAIS E MÉTODOS}

Os experimentos foram realizados na Seção de Radiogenética do Centro de Energia Nuclear na Agricultura (CENA/USP), em Piracicaba-SP, utilizando a espécie tangerina Cleópatra (Citrus reshni Hort.).

Efeito do meio de cultivo dos calos na eficiência de isolamento: Os calos embriogênicos de tangerina Cleópatra foram subcultivados por no mínimo 3 cultivos de 3 semanas, nos seguintes meios de cultura: MT (MURASHIGE \& TUCKER, 1969) suplementado com $5 \%$ de sacarose e 500 $\mathrm{mg} / \mathrm{l}$ de extrato de malte (MT), MT suplementado com $5 \%$ de sacarose, $500 \mathrm{mg} / \mathrm{l}$ de extrato de malte e $10 \mathrm{mg} / 1$ de benzilaminopurina (MT + BAP) e MT suplementado com $4 \%$ de sacarose (MT-S).

A solução enzimática empregada foi composta por $1.0 \%$ de cellulase "Onozuka" RS (Yakult Honsha Co. Ltd., Tokyo, Japan); 1.0\% de macerozyme R-10 (Yakult Honsha Co. Ltd., Tokyo, Japan); $0.2 \%$ de pectolyase Y-23 (Seishin Pharmaceutical Co. Ltd., Tokyo, Japan); $0.7 \mathrm{M}$ manitol; $12.0 \mathrm{mM}$ de cloreto de cálcio; $1.4 \mathrm{mM}$ de $\mathrm{NaH}_{2} \mathrm{PO}_{4}$; e $6.0 \mathrm{mM}$ de MES. $\mathrm{O} \mathrm{pH}$ dessa solução foi ajustado para 5.6 e a filtração foi realizada em membrana de $0.2 \mu \mathrm{m}$ (GROSSER \& CHANDLER, 1987).

Para o isolamento de protoplastos macerou-se com um bastão de vidro $1 \mathrm{~g}$ de calo de cada tratamento em $3 \mathrm{ml}$ de meio $\mathrm{BH}_{3}$ (GROSSER \& GMITTER Jr., 1990) $0.7 \mathrm{M}$, em placa de Petri $(45 \times 20 \mathrm{~mm})$; adicionando-se em seguida, $1 \mathrm{ml}$ da solução enzimática. As placas de Petri foram seladas com parafilme e incubadas a 25 $\pm 2^{\circ} \mathrm{C}$, sob condições de escuro a $50 \mathrm{rpm}$ (GROSSER \& GMITTER Jr., 1990).

A avaliação do experimento foi feita em Câmara de Newbauer através da contagem do número de protoplastos intactos isolados, a intervalos de 1 hora, sendo utilizadas 2 repetições por tratamento.
Efeito do pré-tratamento dos calos com macerozyme: Utilizaram-se calos de tangerina Cleópatra com 3 subcultivos de 3 semanas em meio de cultura MT-S. Os tratamentos consistiram em pré-tratamento dos calos com solução enzimática contendo macerozyme R-10 a $1 \%$, por 1 e 2 horas (BUTTON \& BOTHA, 1975), em condições de escuro a $25 \pm 2{ }^{\circ} \mathrm{C}$, em agitador orbital a $120 \mathrm{rpm}$. Nessa solução enzimática foram utilizados os estabilizadores osmóticos e de membrana empregados na solução enzimática descrita por GROSSER \& CHANDLER (1987). Os resultados foram comparados com um tratamento controle, onde se utilizou o método de digestão da parede celular descrito GROSSER \& GMITTER Jr. (1990). As avaliações dos resultados foram realizadas da mesma forma que no experimento anterior, sendo utilizadas 2 repetições por tratamento.

Em seguida, os protoplastos, isolados a partir de calos subcultivados no meio de cultura MT-S e submetidos a um pré-tratamento enzimático com macerozyme, foram purificados conforme recomendam GROSSER \& GMITTER Jr. (1990). A viabilidade desses protoplastos foi estudada através do emprego do corante azul de metileno na concentração final de $0.01 \%$ (HOOLEY \& McCARTHY, 1980). Foram analisadas a viabilidade de 200 protoplastos após cada isolamento, sendo feitas contagens do número de protoplastos viáveis e mortos em microscópio invertido.

\section{RESULTADOS E DISCUSSÃO}

$\mathrm{Na}$ literatura existem vários protocolos de isolamento de protoplastos de citros como os de SPIEGEL-ROY \& VARDI (1984); KOBAYASHI et al. (1985); GOLDMAN (1988) e GROSSER \& GMITTER Jr. (1990). O protocolo de GROSSER \& GMITTER Jr. (1990), que utiliza a solução enzimática de GROSSER \& CHANDLER (1987), foi escolhido para a avaliação do experimento de isolamento de protoplastos obtidos a partir de calo da variedade tangerina Cleópatra por ser o mais recente e por se aplicar a diversas espécies.

Inicialmente, foram estudados os efeitos da composição do meio de cultivo utilizado na multiplicação de calos e do tempo de digestão enzimática sobre a eficiência de isolamento de protoplastos. No presente estudo, 
notou-se, para todos os meios de cultivo estudados, que o maior número de protoplastos intactos isolados ocorreu após 4 horas de tratamento enzimático dos calos subcultivados (Figura 1). A análise dos trabalhos de isolamento de protoplastos de citros existentes na literatura permite classificar as soluções enzimáticas em dois grupos com relação ao tempo de digestão enzimática: soluções fortes, em que o isolamento de protoplastos a partir de calo ocorre em 4 horas (GOLDMAN, 1988) e soluções fracas, em que o isolamento ocorre em aproximadamente 16 horas (VARDI et al., 1982; SPIEGEL-ROY \& VARDI, 1984). A análise dos resultados do experimento realizado permite incluir, didaticamente, a solução enzimática de GROSSER \& CHANDLER (1987) no grupo das soluções fortes.

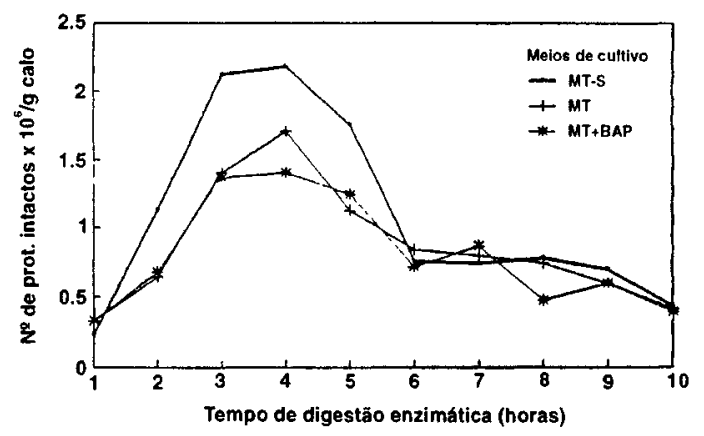

Figura 1 - Efeito da composição do meio de cultivo utilizado na multiplicação de calos de tangerina Cleópatra (Citrus reshni Hort.) na eficiência de isolamento de protoplastos durante a digestão enzimática.

Pela Figura 1 verifica-se, ainda, que os calos subcultivados em meio de cultura com menor teor de sacarose $(4 \%)$ apresentam maior eficiência na liberação de protoplastos quando comparados aos calos cultivados em meio contendo reguladores de crescimento e/ou $5 \%$ de sacarose. Por essa razão, o número médio de protoplastos isolados por grama de peso fresco de calos de tangerina Cleópatra subcultivados nos meios de cultura MT-S, MT e MT+BAP foi de $2.2 \times 10^{6}$, $1.7 \times 10^{6}$ e $1.4 \times 10^{6}$, respectivamente.

Os resultados obtidos no presente estudo estão de acordo com as citações de SHEPARD \& TOTTEN (1977); WALLIN et al.
(1977) e SIMMONDS et al. (1979), os quais verificaram aumento na eficiência de isolamento de protoplastos com a redução na concentração de sacarose dos subcultivos anteriores ao processo de isolamento. WALLIN et al. (1977), atribuíram o aumento na eficiência de isolamento de protoplastos à mudança na composição química da parede celular ocasionada pelo menor teor de sacarose. Este procedimento exige menor quantidade de enzima para $o$ isolamento de protoplastos, reduzindo possíveis efeitos de toxicidade. Neste experimento observou-se aumento pronunciado no crescimento dos calos no meio MT-S. Esses calos eram mais friáveis e, provavelmente, apresentavam maior número de células na fase de crescimento logarítmico, visto que nessa fase as células dos calos são mais uniformes e apresentam parede celular mais fina, possibilitando maior eficiência no isolamento de protoplastos (POWER \& CHAPMAN, 1985).

Durante as contagens de protoplastos deste experimento, observou-se a presença de microcalos compactos que só liberavam protoplastos em suas extremidades, locais onde ocorria contato efetivo com a solução enzimática. Verificou-se, também, que após 10 horas de tratamento enzimático restavam, ainda, alguns aglomerados de células que não apresentavam a parede celular digerida pela solução enzimática. Por essa razão, foi realizado um segundo experimento com o objetivo de avaliar o efeito de um pré-tratamento enzimático na separação das células dos microcalos, visando aumentar a eficiência no isolamento de protoplastos. Para o pré-tratamento dos calos foi utilizada solução de macerozyme a $1 \%$ por 1 e 2 horas, que promoveu uma pré-individualização das células dos calos. De acordo com BUTTON \& BOTHA (1975), o uso de macerozyme, mesmo em concentrações mais elevadas de 2 a $3 \%$, aparentemente não afeta a viabilidade das células, que permanecem intactas após o tratamento.

$\mathrm{Na}$ Figura 2, pode-se verificar o efeito benéfico do pré-tratamento enzimático, com solução contendo macerozyme a $1 \%$, sobre a eficiência no isolamento de protoplastos. Esse tratamento promoveu a duplicação no número de protoplastos intactos isolados por grama de peso fresco de calos de tangerina Cleópatra $\left(4.7 \times 10^{6}\right)$, demonstrando que, muitas vezes, devem ser feitas alterações em protocolos consagrados na literatura visando ajustá-los às condições do laboratório e do 
material biológico disponível. Segundo SHAHIN (1985), embora generalizações possam ser feitas, as condições necessárias ao isolamento e cultivo de protoplastos podem variar consideravelmente de espécie para espécie e de genótipo para genótipo. O mesmo fato foi observado por VARDI $e t$ al. (1982), que verificaram grande variabilidade nos requisitos metodológicos exigidos por diferentes variedades e espécies, principalmente no que se refere às enzimas de maceração e aos açúcares utilizados como estabilizadores osmóticos.

Os resultados relativos à eficiência de isolamento de protoplastos de calos de tangerina Cleópatra foram superiores aos obtidos por GOLDMAN (1988) e CRISTOFANI (1991), as quais ao trabalharem com a variedade laranja Pera isolaram em média $1.37 \times 10^{6}$ e $1.43 \times 10^{6}$ protoplastos/g de peso fresco de calo, respectivamente.

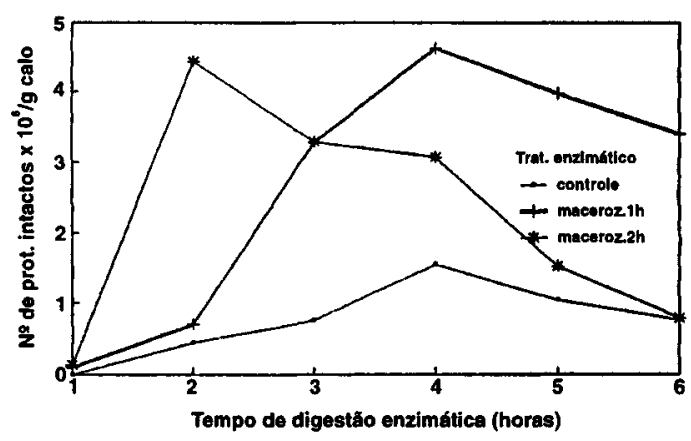

Figura 2 - Efeito de pré-tratamento enzimático de calos com macerozyme sobre a eficiência do isolamento de protoplastos de tangerina Cleópatra (Citrus reshni Hort.).

Embora o tratamento com macerozyme a $1 \%$ por 2 horas tenha proporcionado uma eficiência de isolamento de protoplastos semelhante ao tratamento pré-enzimático por 1 hora, este último deve ser recomendado devido a presença de menor quantidade de células danificadas, o que facilita a etapa de purificação.

Nos experimentos realizados observou-se que, de uma forma geral, calos altamente friáveis, esbranquiçados (sem oxidação) e de rápido crescimento são os que promovem maior eficiência de isolamento de protoplastos.

A viabilidade dos protoplastos isolados a partir de calos de tangerina Cleópatra subcultivados no meio de cultura MT-S sendo realizado o pre-tratamento enzimático com macerozyme $1 \%$ por 1 hora nas condições propostas variou de 81 a $89 \%$. Esses resultados indicam a eficiência do método e se aproximam dos obtidos por GOLDMAN (1988) e CRISTOFANI (1991) que trabalhando com protoplastos isolados da variedade laranja Pera obtiveram de 79.5 a $89.5 \%$ e de 80.7 a $84.0 \%$ de protoplastos viáveis, respectivamente.

\section{CONCLUSÕES}

- método descrito por GROSSER \& GMITTER Jr. (1990) permite o isolamento de protoplastos de tangerina Cleopatra em quantidades satisfatórias para posteriores trabalhos de hibridação somática via fusão de protoplastos. No entanto, alterações na metodologia, relacionadas a redução do nível de sacarose e ausência de reguladores de crescimento no meio de cultivo dos calos e a adoção de um prétratamento enzimático dos mesmos com macerozyme, permitem aumento da eficiência de isolamento de protoplastos viáveis.

\section{REFERENCIAS BIBLIOGRÁFICAS}

BUTTON, J.; BOTHA, C.E.J. Enzymic maceration of Citrus callus and the regeneration of plants from single cells. Joumal of Experimental Botany, Oxon, v.26, n.94, p.723-729, 1975.

CRISTOFANI, M. Adaptação de metodologias de cultura de tecidos visando o melhoramento através de indução de mutaçōes em Citrus sinensis (L) Osbeck cv. Pera. Piracicaba, 1991. 185p. Dissertação (Mestrado) Escola Superior de Agricultura "Luiz de Queiroz", Universidade de São Paulo.

FAOQUARTELY BULLETIN OF STATISTICS. Rome, 1992. v.5, 117p.

GOLDMAN, M.H.S. Cultura de tecidos nucelares, isolamento e radiossensitividade de protoplastos de Citrus sinensis (L) Osbeck cv. Pera. Piracicaba, 1988. 127p. Dissertação (Mestrado) - Escola Superior de Agricultura "Luiz de Queiroz", Universidade de São Paulo.

GROSSER, J.W.; CHANDLER, J.L. Aseptic isolation of leaf protoplasts from Citus, Poncinus, Poncirus $X$ Citrus hybrids and Severinia for use in somatic hybridization experiments. Scientia Horticulturae, Amsterdam, v.31, n.253-257, 1987. 
GROSSER, J.W.; GMITTER JÚNIOR, F.G. Protoplast fusion and citrus improvement. Plant Breeding Reviews, New York, v.8, p.339-374, 1990.

HOOLEY, R.; McCARTHY, D. Extracts from virus infected hypersensitive tobacco leaves are detrimental to protoplast survival. Physiological and Molecular Plant Pathology, London, v.16, p.25-38, 1980.

KOBAYASHI, S.; IKEDA, I.; UCHIMIYA, $\mathbf{H}$. Conditions for high frequency embryogenesis from orange (Citrus sinensis Osb.) rotoplasts. Plant Cell, Tissue and Organ Culture. Dordrecht, v.4, p.149$159,1985$.

MURASHIGE, T.; TUCKER, D.P.H. Growth factor requirements of citrus tissue culture. INTERNATIONAL CITRUS SYMPOSIUM,1., Riverside, 1969. Proceedings... v.3, p.1155-1161.

OHGAWARA, T.; KOBAYASHI, S.; OHGAWARA, E.; UCHIMIYA, H.; ISHII, S. Somatic hybrid plants obtained by protoplast fusion between Citrus sinensis and Poncirus trifoliata. Theoretical and Applied Genetics, Berlin, v.71, p.1-4, 1985.

POWER, J.B.; CHAPMAN, J.V. Isolation, culture and genetic manipulation of plant protoplasts. In: DDXON, R.A., ed. Plant cell culture. Oxford, 1985 - p.37-66.

SHAHIN, E.A. Totipotency of tomato protoplasts. Theoretical and Applied Genetics, Berlin, v.69, p.235-240, 1985 .
SHEPARD, J.F.; TOTTEN, R.E. Mesophyll cell protoplasts of potato. Plant Pysiology, Rockville, v.60, p.313-316, 1977 .

SIMMONDS, J.A.; SIMMONDS, D.A.; CUMMING, B.G. Isolation and cultivation of protoplasts from morphogenetic callus cultures of Lilium. Canadian Journal of Botany, Ottawa, v.57, p.512-519, 1979.

SPIEGEL-ROY, P.; VARDI, A. Citrus. In: AMMIRATO, P.V.; EVANS, D.A.; SHARP, W.R.; YAMADA, Y., ed. Handbook of plant cell culture; crop species. New York, MacMillan, 1984. v.3, p.355-72.

VARDI, A.; SPIEGEL-ROY, P.; GALUN, E. Plant regeneration from Citrus protoplasts: variability in methodological requirements among cultivars and species. Theoretical and Applied Genetics, Berlin, v.62, p.171-176, 1982.

WALLIN, A.; GLIMELIUS, K.; ERIKSON, T. Pretreatment of cell suspension as a method to increase the protoplast yield of Aplopappus gracilus. Physiologia Plantarum, Copenhagen, v.40, p.307$311,1977$.

Entregue para publicação em 30.05.94 Aceito para publicação em 03.08 .94 